\title{
The Effect of Body image and Self-esteem on Selfie addiction among fresh female students at Ahfad University-Omdurman/Sudan.
}

Dr. Ibrahim Abdel Rahim Ibrahim Humaida

\begin{abstract}
This study aimed to examine the effect of body image and self-esteem on selfie addiction among fresh female students at Ahfad University(Sudan), as well as to investigate the correlation between body image and self-esteem. To achieve those objectives, the researcher adopted the descriptive research method. The sample included (400) female students whose average age was (22.5) years, selected by using a simple random sample. The study was conducted by administering three scales. The results of the study indicated that $(50 \%)$ of the sample suffered from the selfie addiction between moderate to severe levels. There was a significant correlation between selfie addiction, self-esteem and body image. Moreover, it was found that both body image and self-esteem had a predictive ability to increase likelihood of selfie addiction among females. The study recommended that professionals should consider preparing prevention programs for those who have traits of a selfie addiction behavior.
\end{abstract}

Keywords: Body image, Self-esteem, Selfie addiction, females, Sudan. 


\section{Introduction}

In the Eastern nations, taking pictures for memories was not a big part of the culture, until selfies came into existence. Today, taking a picture of yourself (selfies) has become a phenomenon worldwide, especially among females at young ages. In the past few years, a great number of individuals, practiced taking selfies for themselves, which made the phenomenon of the selfies one of the interesting topics for researchers in the socio-psychological field. As a result, some research was conducted to examine this phenomenon and its relationship with individuals' personalities and their self-esteems (March \& McBean, 2018).

Recently scholars have started to examine selfie-related behavior, with an emphasis on young women. However, few studies have focused on individual's selfie considering different variables such as a close friend, body image and selfesteem of young females. Concerning the rapid growth of investigation regarding self-photographing, which is considered as an aspect of social media and social networking sites, that has been a common phenomenon in everyday life. On the other hand, mobile phones and smart devices that have recently attracted millions of people all over the globe, emphasized by remarkable developments in the technology, have enhanced the individuals to communicate with each other, create personal profiles, in addition to post pictures and photos. Thus, social ties seem to be growing particularly among fresh university students across cultures (Haggard, K.M.2014).

\subsection{Statement of the research problem:}

To many researchers, taking selfies is rather controversial issue. The American Psychiatric Association (APA), confirmed that taking selfies is a mental disorder. Some psychologists view selfies as a form of obsessive compulsive disorder. However, there are some positive aspect of taking selfies as it is a kind of selfexploration and communication.

This current research seeks to answer the following questions:

1.What the level of selfie addiction among fresh female students in Ahfad university?

2. Is there any significant correlation between selfie addiction, self-esteem, and body image?

3. Can selfie addiction be predicted by self-esteem and body image? 
The Effect of Body image and Self-esteem on Selfie addiction among fresh female students at Ahfad University-Omdurman/Sudan.- Dr. Ibrahim Abdel Rahim Ibrahim Humaida

\subsection{Objectives:}

General: To identify the prevalence of selfie addiction in fresh female students. Specific: To highlight the nature of relationship between selfie addiction, selfesteem, and body image.

\subsection{Hypotheses}

1- Selfie addiction among fresh female students was significantly moderate.

2- There was a significant correlation between selfie addiction, self-esteem, and body image.

3- Body image and self-esteem could predict selfie addiction.

\section{Literature Review}

\subsection{Selfies addiction and Self-esteem}

A selfie is a picture that is taken by an individual to himself without the assistance of others, by using a fast self-portrait made with a smartphone or webcam that can be immediately posted and distributed into a social media (March \& McBean, 2018), According to Oxford Dictionaries, "Selfie." is the word of the year for 2013, and the word was invented to describe the act of taking self-portrait and sharing it on social networks. Taking and sharing selfies have become common with the advent of various smart devices and social media (Sung, Lee, Kim, \& Choi, 2016), As the phenomenon of taking and sharing selfies has become widespread between individuals around the world, several researchers have studied selfies from different socio-psychological perspectives. These studies can be classified into two main categories: studies that investigate how personality traits are related to selfies, and studies that investigate how people socially perceive selfies (Shin, Kim, \& Chong, 2017).

Erik Erikson's model of ego development encompasses a series of eight psychosocial tasks that intensify to a crisis or turning point in an ordered sequence extending across the life cycle. The majority of freshmen students fall in Erikson's fifth developmental stage which is the age between 12 and 18 years. This stage is described as the stage of (Identity vs. Role Confusion), During this stage of adolescence, children explore their independence and develop a sense of self. If this stage, went successfully, then an individual will develop an ability to stay true 
to oneself, have positive self-esteem and clear identity. However, a failure leads to confusion and a weak self-image. adolescence who don't have a strong sense of their own identity can easily get influenced by others around them, especially peers. This stage is critical because if they get wrongly influenced by peers they can easily get into awful habits (Hattangadi,2019), In this research, looking from the lens of the human developmental theory was imperative as it provides a clear explanation of the characteristics of individuals at freshman students' developmental stage in specific as well as clarifying the logic behind their behaviors and looking in-depth into the surrounding components that influence them. Moreover, understanding human development stages theory is beneficial to support this study with a strong recommendation on how to deal with any conflict that might appear in these development stages professionally.

Personal identity and a sense of self are the main concerns for adolescence during their developmental stages, which is the stage of a transition from childhood to adulthood. If this stage went successfully, individuals will turn into their adulthood stage with a clear vision of their identities and a high sense of self, otherwise, individuals might experience an identity crisis that will negatively impact their self-esteem and self-identity (McLeod \& Erikson, 2008), The issue of low self-esteem and identity concern can emerge on individuals via different external behaviors. Past studies had found that talking a lot of selfies can be one of the behaviors that indicate a divergence on an individual's self-esteem (March \& McBean, 2018), In an exploratory study consisted of 15 in-depth interviews with women who were 19-30 years of age, the searchers found that the issue of self-esteem can explain the behavior of taking a lot of selfies, in which woman who is deeply engaged in taking a lot of selfies is for the purpose of enhancing their self-esteem (Pounders, Kowalczyk, \& Stowers, 2016), Moreover, a recent study conducted by Biolcati and Passini (2018), found a positive correlation between the selfie posting behavior and the negative self-esteem of individuals, and people with high self-esteem do not get to be involved in selfie posting behavior.

The image of the body is found to be a concern for individuals at the adolescent age and it plays a significant role in their self-esteem. When they are satisfied with their body image, their confidence level upsurge, thus, a low selfesteem and depressive signs emerge in their behaviors (Paxton et al., 2006). A study that was conducted by Grossbard, Lee, Neighbors, and Larimer (2009) examined body image concerns and its impact on the issue of self-esteem in male 
The Effect of Body image and Self-esteem on Selfie addiction among fresh female students at Ahfad University-Omdurman/Sudan.- Dr. Ibrahim Abdel Rahim Ibrahim Humaida

and female college students and found that the contingent self-esteem issue is positively correlated with a more negative body image concerns, and it would be more evident among female college students compared to male college students. In a similar study, Sira and White (2010) indicated that body image is a combination that depends upon inner biological and psychological components and is it an important aspect of the individual's self-esteem and mental health across their lifetime. Longitudinal students had addressed the impact of a negative view of the body image on individuals with considering their ages and genders (Mellor et al., 2010). However, less research attention has been directed toward a translation of this internal, unconscious, self-esteem conflict into more obvious external behaviors. Thus, this study came to spot the light on the phenomena of the intensive selfies behaviors that young adults are involved in these days to seek a better understanding of the phenomenon of selfies, particularly in relation to the body image and self-esteem of young females.

\subsection{Selfie addiction and Body Image}

Taking a lot of selfies is one of the behaviors that searchers in the field had found to be an indication of the dissatisfaction toward individuals' body image and a sign of low self-esteem. Mills, Musto, Williams, and Tiggemann (2018) found in their experimental study that women who reported to have a lower perception of their physical appearance and attractiveness tend to take and post more selfie compared to others who are more satisfied with their body image. From another angle, previous researches have also found that compared to men, women tend to be engaged in more photo-enhancement behaviors for a positive self-presentations and it was concluded that taking and posting a selfie is a risk behavior that can negatively impact young women's body image and self-esteem (Toma \& Hancock, 2010; Haferkamp, Eimler, Papadakis, \& Kruck, 2012), In a similar study, a group of researchers has found that the concern about photo manipulation and selfie posting pictures might be risky associated with body dissatisfaction for both men and women at the same level (Lonergan, et al., 2019). 


\section{Method}

\subsection{Study Design}

The researcher adopted the descriptive research methodology in which selfreport measures can be used on accurately selected samples. It is a flexible method that can also be utilized to study a wide range of basic and applied researches.

\subsection{Participants}

The participants were (400) fresh female students at Ahfad university of women, which was established in 1966, and it is a private women's university in Omdurman- Sudan. They ranged in age from 19-24 years old $(\mathrm{M}=22.5, \mathrm{SD}=0.61)$, and their GPAs ranged from (80\% to $98.8 \%$ ). These participants were selected through simple random sampling. They all have a selfie camera in their mobile phones.

\subsection{Instruments}

1.Selfie Addiction Scale: The selfie addiction scale was prepared electronically by the researcher. After matching items with selfie addiction symptoms in International Classification of Diseases (ICD-11), and after reviewing previous studies, to ensure understanding or modification of the items. The exploratory experiment was conducted on a sample of 12 students. It consists of 16 items, all of the self-report type, which individuals respond to in the light of a 5-point LikertType scale (1=Never, 2=Rarely, 3=Sometimes, 4=Often, and 5= Always), and the higher scores indicate a high level of intensity and frequency for selfie behavior. The total score ranges from 16 - 80 scores. The validity of the scale was confirmed by the internal consistency through the correlation between each item and total score ranged between (40 and 69), which indicates the validity of the scale. The Cronbach's alpha coefficient for all 16-items was (0.87), and split-half coefficient was (0.82).

2.Body Image Scale: This scale was developed by Annabelle, (2011), consisting (27)items and is located in two dimensions: First: a person's perception of his body, which is positive or negative, and includes the following items: 1, 2, 4, 5, 6, 7, 9, 10, 12, 13, 16, 17, 19, 20, 21, 23, 24, 25, 26. Second: Person's perception of his body through the views of others such as family, friends and colleagues, and includes the following items: $3,8,11,14,15,18,22,27$. All items was self-report type, which individuals respond to in the light of a 5-point Likert-Type scale ( $1=$ Never,2=Rarely, $3=$ Sometimes,4=Often,and5= Always), and the higher scores 
The Effect of Body image and Self-esteem on Selfie addiction among fresh female students at Ahfad University-Omdurman/Sudan.- Dr. Ibrahim Abdel Rahim Ibrahim Humaida

indicate a high level of Positive body image and satisfaction with the shape of his body. The total score ranges between $27-80$ score. The validity of the scale was confirmed by the internal consistency through the correlation between each item and the total score ranged between (.29 and .73), indicating validity of the scale. The Cronbach's alpha coefficient for all 27-items was (0.88), and the split-half coefficient was 0.87 .

3. Self - esteem Scale: This scale was developed by Youssef (2011), consisting (14) items. All items were self-report type, which individuals respond to in the light of 5-point Likert-Type scale (1=Never, 2=Rarely, 3=Sometimes, 4=Often, and $5=$ Always), and the higher scores indicate a high level of A high sense of selfworth or personal value. The total score ranges between 14-70 score. The validity of the scale was confirmed by the internal consistency through the correlation between each item and the total score ranged between (.44 and .68), indicating validity of the scale. The Cronbach's alpha coefficient for all 14-items was (0.85), and the split-half coefficient was (0.76).

\subsection{Data Analysis}

For analyzing the data gleaned from the study, the researchers employed (SPSS), using the following statistical methods: Pearson's Correlation Coefficient, and multiple regression.

\section{Results}

The level of selfie addiction among fresh female students at Ahfad University was interpreted in terms of three categories. These categories were as follows: Mild selfie addiction (16 - 37), Moderate selfie addiction (38-53), Severe selfie addiction (54-80). In light of these criteria, the frequency and percentage of the distribution of participants in selfie addiction were identified, as shown in both Table 1 and Figure 1.

Table (1) Shows the level of selfie addiction among female students $(\mathrm{N}=400)$

\begin{tabular}{|c|c|c|}
\hline Level of selfie addiction & Frequency (n) & Percentage (\%) \\
\hline Mild & 200 & $50 \%$ \\
\hline Moderate & 130 & $33 \%$ \\
\hline Severe & 70 & $17 \%$ \\
\hline Total & 400 & $100 \%$ \\
\hline
\end{tabular}


The result indicated that the largest category of selfie addiction is mild (200 students; 50\%), the students did not demonstrate selfie addiction on the scale.

Table (2): Pearson's Correlation between selfie addiction, self-esteem, and body image.

\begin{tabular}{|l|l|c|}
\hline \multicolumn{1}{|c|}{ Variables } & R & P. value \\
\hline Selfie addiction & $.78^{* *}$ & .05 \\
\hline Self-esteem & $.77^{* *}$ & .05 \\
\hline Body image & $.65^{* *}$ & .05 \\
\hline
\end{tabular}

** Correlation is significant at the 0.05 level (2-tailed).

Correlation analysis indicated that there was a significant correlation between selfie addiction, self-esteem, and body image.

Table (3) Multiple Regression Analysis of predictors.

\begin{tabular}{|c|c|c|c|c|c|c|}
\hline \multirow[t]{2}{*}{ Predictors } & \multicolumn{2}{|c|}{ Model 1(SA) } & \multicolumn{2}{|c|}{ Model 2(SE) } & \multicolumn{2}{|c|}{$\begin{array}{l}\text { Model } \\
\text { 3(BI) }\end{array}$} \\
\hline & b & $\mathbf{t}$ & $\mathbf{b}$ & $\mathbf{t}$ & b & $\mathbf{t}$ \\
\hline $\mathbf{S A}$ & $12^{*}$ & 2.57 & $.20^{*}$ & 4.17 & .09 & 1.88 \\
\hline S E & $14^{*}$ & 3.21 & $.31^{* * * *}$ & 5.11 & .08 & 1.77 \\
\hline B I & $15^{* * *}$ & 4.31 & $.54^{* *}$ & 6.21 & $.09^{*}$ & 1.99 \\
\hline $\mathbf{R}^{2}$ & & $03^{* *}$ & $.08^{* * *}$ & & $.14^{* *}$ & \\
\hline $\mathbf{F}$ & & 3.86 & 11.65 & & 17.44 & \\
\hline
\end{tabular}

SA: selfie addiction; SE: self-esteem; BI: body image. 
The Effect of Body image and Self-esteem on Selfie addiction among fresh female students at Ahfad University-Omdurman/Sudan.- Dr. Ibrahim Abdel Rahim Ibrahim Humaida

$$
\mathrm{P}^{*} \leq .05 ; \mathrm{P}^{* *} \leq .01 ; \mathrm{P}^{* * *} \leq .0001
$$

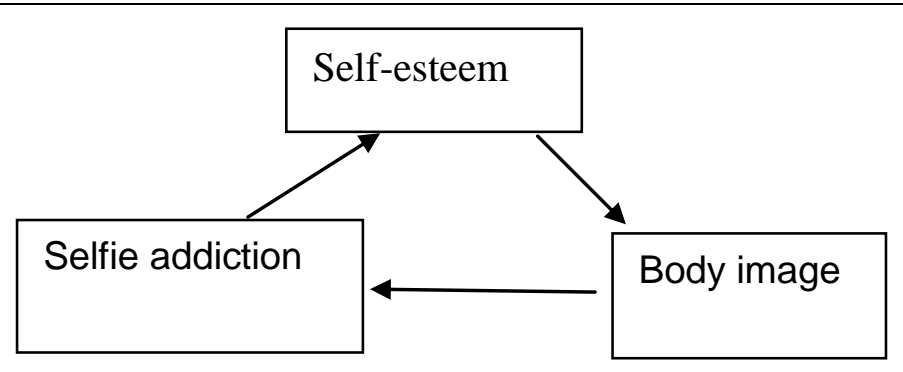

Figure 1. The mutual effects of both self-esteem and body image on selfie addiction.

\section{Discussion}

The results of the first hypothesis indicated that the participants are involved in this behavior in a level between moderate to severe, which supported the previous studies that presented the selfie addiction as a current phenomenon that needs to be considered from a psychological perspective (Wang, Yang, \& Haigh, 2017). This is an indication for their psychosocial adjustment, i.e., despite their use of mobile, they did not suffer from selfie addiction. In the next largest category of moderate selfie addiction (130 students; 33\%). This category might benefit from some prevention programs so that the risk factors do not increase their degree of selfie addiction. The last category of severe selfie addiction (70 students; 17\%), includes those who need treatment programs, either individual or group psychotherapy to reduce the level of selfie addiction (Bothina, E.S.2019).

Concerning the result of the second hypothesis, it was found that there was a significant correlation between selfie addiction, self-esteem and body image. At the adolescence developmental stage, friendship is valuable and it is considered the main source of influence and major support in life (Hattangadi, 2019) \& (Gorrese, 2013). Moreover, this finding supported by other researchers who found that body satisfaction is one of the main factors that influence individuals' self-esteem (Sira \& White, 2010), Children's self-esteem is influenced by their body image and physical appearance and as they grow up into adolescence and adulthood, individuals' self- 
esteem is directly related to how they perceive their body satisfaction (Gurari, Hetts, \& Strube, 2006).

One of the major findings of the study showed that the positive body image has a predictive ability to increase selfie addiction. This interesting finding was different than many previous studies that found a tendency from individuals with a lower perception of their physical appearance and body image to take more selfie compared to others who are more satisfied with their body image (Toma \& Hancock, 2010; Haferkamp, Eimler, Papadakis, \& Kruck, 2012), However, in this current study, the finding can be explained that individuals at these developmental stages who are satisfied by their physical appearance, tend to use tools such as selfie to share this notion of themselves with others. Thus, the reason that people with positive body image tend to take more selfies could be because they needed constant attention, social validation and they relied too much on the response of others to maintain their high self-esteem.

The third hypothesis's result found that Body image and self-esteem could predict selfie addiction. Self-esteem is defined as an individual's overall selfevaluation of one's worth (Rosenberg, 1965; Weiten, 2004), According to Amirazodi \& Amirazodi (2011), the individuals' self-esteem expresses the evaluation and the respect they make to themselves. When individuals are internally satisfied, they do not need to be involved in any external behavior or fake tools for self- presentation. Many previous studies have supported this finding as they presented a relationship between taking a lot of selfies and having low self-esteem. In a similar study that was conducted by Blades (2014), the result showed that $60 \%$ of the females who are involved in the behaviors of taking a lot of selfies admitted having low selfesteem. In a similar result, Biolcati and Passini (2018), found a positive correlation between the selfie posting behavior and the negative self-esteem of individuals, and people with high self-esteem do not get to be involved in selfie posting behavior. Thus, individuals who have high self-esteem do not use tools such as selfies for self-representation because they are internally satisfied (Gillen, M.2020). 


\section{Conclusion:}

This research was conducted to investigate the level of selfie addiction among fresh female students. The study revealed that $50 \%$ of participants were moderately addicted to selfies.

The result also found that there was a positive correlation between selfie addiction, body image and self-esteem. Further, it was found that both self-esteem and body image were predictors to increase selfie addiction among female students.

The trend of photography has created a space positive Unfortunately, it also found a negative expression which makes me assure that the creators and developers of the means and modern technological tools, including cameras of those who have studied the human psyche deeply, they are fully aware that everyone has narcissism. All individuals have some narcissism and this is part of the nature of the human psyche, and there is no doubt that reports confirmed that selfie is a psychological disorder.

\section{Recommendations}

1- It is important for mental health professionals to explore how the individual uses selfies as an important part of a mental health assessment.

2- Attempts need to be made at personal and societal levels to reduce selfie addiction among females.

3- Health professionals need to provide healthy ways for addicts to spend their time.

\section{Suggestions for Further Researches:}

1- An in depth study can be done using a more representative samples.

2-Large surveys and quantitative analysis with more relevant variables such as gender and age will give precise results.

3. A cross-cultural study should be carried out to investigate the prevalence of selfie addiction among the youth. 


\section{References:}

1. Annabelle S. The Relationships Among Body Image, Self-esteem and Depression to a Sample of University Students. Journal of Psychological and Educational Research, 2011.Vol. 1, pp. 187-235.

2. Amirazodi F., \& Amirazodi M. Personality traits and self-esteem. ProcediaSocial and Behavioral Sciences, 2011.Vol. 29, pp. 713-716.

3. Biolcati R., \& Passini, S. Narcissism and self-esteem: Different motivations for selfie posting behaviors. Cogent Psychology,2018, no. 5.pp. 12-29.

DOI:10.1080/23311908.2018.1437012

4. Blades N. Selfie addiction is surely a sign of low-self-esteem. Retrieved from http://www.dailystar.co.uk/news/latest-news/400572/Psychology-studyreveals- insecurity-of-selfie-addicts, 2014.

5. Bothina E.S. (2019). Effect of selfie addiction on self-esteem, body image, and academic achievement among faculty of nursing students. Egyptian Nursing Journal, 2019. Vol.16, pp. 80-91.

6. Clay D., \& Ditmar H. Body Image and Self-esteem among adolescent girls: Testing the influence of sociocultural factors. Journal of Research on Adolescence, 2019, no. 15, pp.451-477.

7. Dihr A., Pallesen S., Torsheim, T., \& Andreassen C. Do age and gender-related differences exist in selfie-related behaviors? Computers in Human Behavior,2016, no. 63, pp. 549-555. DOI: 10.1016/j.chb.2016.05.053.

8. Gillen M. (2020). Associations between positive body image and indicators of men and women mental and physical health. Body Image. Vol.13, pp.67-74.

9. Gorrese A., \& Ruggieri R. Peer attachment and self-esteem: A meta-analytic review. Personality and Individual Differences, 2013.Vol. 55, no. 5, pp. 559568. DOI: 10.1016/j.paid.2013.04.025.

10. Grossbard J. R. Lee C. M. Neighbors C., \& Larimer M. E. Body image concerns and contingent self-esteem in male and female college students. Sex roles, 2009. Vol. 60, pp.198-207.

11. Gurari I. Hetts J. J., \& Strube M. J. (Beauty in the" I" of the beholder: Effects of idealized media portrayals on implicit self-image. Basic and applied social psychology,2006, no. 28, pp.273-282.

12. Haferkamp N., Eimler S. C., Papadakis A. M., \& Kruck J. V. Men are from Mars; women are from Venus? Examining gender differences in self- 
The Effect of Body image and Self-esteem on Selfie addiction among fresh female students at Ahfad University-Omdurman/Sudan.- Dr. Ibrahim Abdel Rahim Ibrahim Humaida

presentation on social networking sites. Cyber psychology, Behavior, and Social Networking, 2012, no. 15, pp. 91-98.

13. Haggard K.M. Selfie Culture and Social Network. Retrieved from http://people.ucsc.edu/2014.

14. Hattangadi V. The eight stages of human development. Financial Express,2019. DOI: 10.1007/s10583-017-9312-z

15. Lonergan A. R., Bussey K., Mond J., Brown O., Griffiths S., Murray S. B., \& Mitchison D. Me, my selfie, and I: The relationship between editing and posting selfies and body dissatisfaction in men and women. Body Image, 2019. Vol. 28, pp. 39-43. DOI: 10.1016/j.bodyim.2018.12.001

16. March E., \& McBean T. New evidence shows self-esteem moderates the relationship between narcissism and selfies. Personality and Individual Differences, 2018, no. 130, pp.107-111. DOI: 10.1016/j.paid.2018.03.053

17. Mellor D., Fuller-Tyszkiewicz M., McCabe M. P., \& Ricciardelli L. A. Body image and self-esteem across age and gender: A short-term longitudinal study. Sex roles, 2010, no. 63, pp. 672-681.

18. Mills J., Musto S., Williams L., \& Tiggemann M. Self-harm: Effects on mood and body image in young women. Body Image, 2018. Vol. 27, pp. 86-92. http://dx.DOI:10.1016/j.bodyim. 2018.08.007

19. Nguyen A. J. Exploring the selfie phenomenon: The idea of self-Presentation and its implications among young women. Master thesis. Smith College School for Social Work Northampton.2014, pp.50-60. https://dspace.smith.edu/bitstream/handle/ 11020/24476/NguyenAFinal.pdf.

20. Paxton S. J., Neumark-Sztainer D., Hannan P. J., \& Eisenberg M. E. Body dissatisfaction prospectively predicts depressive mood and low self-esteem in adolescent girls and boys. Journal of Clinical Child \& Adolescent Psychology, 2006. Vol. 35, pp. 539-549.

DOI:10.1207/s15374424jccp3504_5.

21. Poe J. The link between "likes" and self-worth: how women use selfies on Instagram for self-presentation and the effects of social comparison. 2015, In 14th annual celebration for undergraduate research and creative performance, paper 24. 
22. Pond J. Treading Water: Considering Adolescent Characters in Moratorium. Children's Literature in Education, 2018, no. 49, pp. 87-100.

23. Pounders K., Kowalczyk C. M., \& Stowers K. Insight into the motivation of selfie postings: impression management and self-esteem. European Journal Marketing, 2016.Vol. 50, pp.1-14.

24. Shin Y., Kim, M., Im, C., \& Chong S. C. Selfie and self: The effect of selfies on self-esteem and social sensitivity. Personality and Individual Differences, 2017, no. 111, pp. 139-145. DOI: 10.1016/j.paid.2017.02.004

25. Sira N., \& White C.P. Individual and familial correlates of body satisfaction in male and female college students. Journal of American College Health, 2010.Vol. 58, pp.507- 513.

26. Sung Y., Lee J., Kim, E., \& Choi S. M. Why we post selfies: Understanding motivations for posting pictures of oneself. Personality and Individual Differences, 2016, no. 97, pp.260-265. DOI: 10.1016/j.paid.2016.03.032

27. Toma C. L., \& Hancock J. T. Looks and lies: The role of physical attractiveness in online dating self-presentation and deception. Communication Research, 2010. Vol. 37, no. 3, pp. 335-351.

28.Wang R., Yang F., \& Haigh M. M. Let me take a selfie: Exploring the psychological effects of posting and viewing selfies and groupies on social media. Telematics and Informatics, 2017. Vol.34, no. 4, pp.274-283. DOI: 10.1016/j.tele.2016.07.004

29. Weiten W. Psychology themes and variations. Belmont, CA:

Wadsworth, Thomson Learning, 2004. 